\title{
O CARÁTER SINGULAR DA LÍNGUA NA ANÁLISE DO DISCURSO
}

\author{
Maria Cristina Leandro Ferreira
}

RESUMO: Le but de ce travail c'est d'examiner les principaux concepts du domaine discursif, à partir de la théorie de l'École Française de l'Analyse $d u$ Discours. Pour observer ces concepts, on analyse les traits spécifiques de chacun et, particulièrement, celui de langue. À partir de ces analyses, on peut soutenir que la notion de langue, telle quelle est formulée dans de quadre théorique de l'analyse du discours, est essentielle pour singulariser notre théorie parmi les autres soi-disantes analyses du discours.

PALAVRAS-CHAVE: língua, discurso, história, sujeito, ideologia, sentido

\section{INTRODUÇÃO}

Pretendo nesta comunicação fazer um passeio pelo campo discursivo, parando aqui e ali para destacar algum cenário que seja mais sugestivo e desperte de modo especial nossa curiosidade e interesse. De antemão, aviso que o terreno é dado a armadilhas, obstáculos e pode levar algum incauto a não achar o caminho. Por isso, é recomendável que a trilha seja seguida com cuidado e persistência, dando-se bastante atenção às

Maria Cristina Leandro Ferreira é professora da Universidade Federal do Rio Grande do Sul. 
formulações e referências fornecidas.

As ferramentas indispensáveis para essa caminhada encontramse na caixa dos conceitos ${ }^{1}$, que devem estar muito limpos, afiados e compatíveis com o que pretende o eventual interessado.

Convido, pois, a todos, a serem parceiros nessa inquietante aventura teórica: a aventura do discurso. ${ }^{2}$

\section{A CAIXA DOS CONCEITOS}

A Análise do Discurso de tradição francesa (AD) apresenta, como é sabido, um quadro teórico-conceitual constituído de categorias que circulam livremente em outros aparatos teóricos. Isto se deve às particularidades da formação de seu campo epistemológico que abrange a lingüística, a teoria do discurso propriamente e o materialismo histórico, cada uma dessas regiões com seus termos-chaves correspondentes (PÊCHEUX e FUCHS, 1975, p.8). Daí decorrem, por exemplo, num primeiro momento, os conceitos de língua (crucial na lingüística), discurso (objeto da teoria do discurso) e história (relacionado ao materialismo histórico). Se considerarmos ainda que, segundo os autores, as três regiões estão articuladas/ atravessadas por uma teoria da subjetividade de natureza psicanalítica, iremos agregar o conceito de sujeito. Ficam faltando, a rigor, dois conceitos a serem incorporados, o de ideologia, inseparável de uma teoria materialista, e o de sentido, já que estamos tratando de uma teoria do discurso, ou ainda, de uma teoria materialista dos sentidos.

Ocorre que tais conceitos, ainda que vinculados a uma região de origem específica, ao migrarem para a análise do discurso, vão ser incorporados à teoria que os acolheu e encontrarão aí um território próprio, com escopo definido e limites diferenciados. Daí o cuidado que o analista de discurso deve ter ao empregar noções já cunhadas, como as de língua, ideologia e história, por exemplo, definindo-as de modo compatível ao novo quadro teórico em questão.

Qualquer uma das noções teóricas arroladas apresenta especificidades e singularidades que mereceriam uma análise detalhada e aprofundada. Neste trabalho faremos apenas um breve registro ao conjunto desses termos, já que o nosso foco é a língua.

${ }^{1}$ A expressão 'caixa de ferramentas' é encontrada em G.Deleuze, em entrevista com M.Foucault, como metáfora de como deve funcionar uma teoria. (1974, p.141)

${ }^{2}$ Fazemos aqui uma referência explícita ao belo livro de D.Maldidier (1990) "L'inquiétude du discours", reunindo textos escolhidos de M.Pêcheux. 


\section{a) a história:}

Começando pela noção de história, diremos, em primeiro lugar, que na Análise do Discurso história nada tem a ver com contexto, com algo que fica de fora, determinando, eventualmente, o que acontece no interior de um processo. Na teoria do discurso da corrente francesa, o conceito de história faz parte da ordem do discurso e isso já impõe uma diferença. Costuma-se, em certas análises de discurso, elidir a história, o que as aproxima muito da pragmática; ou então, denegá-la, como acontece com a tendência formalista-logicista, o que encobre as condições em que se realiza a prática lingüística do sujeito falante e reforça o imaginário do sujeito com pleno controle sobre sua língua. É interessante lembrar que o próprio Pêcheux, já mostrava-se preocupado com o risco de certos analistas ficarem cegos em relação à história e surdos em relação à língua (PÊCHEUX, 1981, p.8).

Paul Henry (1994), por sua vez, afirma que a história não é evolução, nem cronologia, mas sim, sentido. Ele refuta, portanto, o caráter de descrição empírica normalmente atribuído à história, como se fosse mero relato de acontecimentos. A história necessita do discurso para existir, assim como a língua necessita dela para significar. Pêcheux resume a questão ao afirmar que "a história está na língua", já que os fatos históricos existem sob efeito de interpretação.

A noção derivada de história e que está mais próxima da Análise do Discurso é a de historicidade que tem a ver precisamente com a inscrição da história na língua. Nessa perspectiva, a exterioridade não tem a objetividade empírica daquilo que está "fora da linguagem", pois constitui-se no próprio trabalho dos sentidos atuando em determinados textos, enquanto discursos.

\section{b) a ideologia:}

Quanto ao conceito de ideologia trabalhado no materialismo histórico e dialético, sobretudo com a formulação atribuída a Althusser, apresentase na perspectiva teórica por nós eleita com uma tonalidade distinta, conferida pelo viés discursivo. Assim sendo, a ideologia não é um conjunto de representações nem a ocultação da realidade, nem tampouco um "defeito" dos que não têm consciência. Discursivamente, a ideologia, como prática significante, aparece como efeito da relação necessária da língua com a história, no processo de constituição dos sujeitos e dos sentidos. Por um mecanismo ideológico, aquilo que é constitutivo aparece como já-lá, como já-dito ; o efeito é, então, o da evidência do sentido e a impressão do sujeito como origem do que 
diz. Este é um trabalho da ideologia por essa ótica discursiva.

A ideologia vai ainda apontar para uma interpretação de sentido em certa direção, determinada pela relação da língua com a história. Entre o mundo e a linguagem está presente uma contradição, e a ideologia vai constituir-se precisamente no trabalho desta contradição.

\section{c) o sujeito:}

Um outro conceito intimamente ligado ao anterior é o de sujeito. Ainda que se tenha afirmado, no início do artigo, que a Análise do Discurso opera com uma teoria da subjetividade de natureza psicanalítica, é preciso ter presente que o sujeito do discurso não é o sujeito da psicanálise. Esta trabalha com o sujeito do desejo, do inconsciente; na teoria do discurso, inconsciente e ideologia estão materialmente ligados pela linguagem. Na Análise do Discurso, mais do que o sujeito, interessam as posiçõessujeito, uma vez que o sujeito é pensado discursivamente como uma posição entre outras. Não há, portanto, uma forma de subjetividade, mas um lugar que o sujeito ocupa para ser sujeito do que diz.

Na Análise do Discurso, os processos discursivos vão se desenvolver pelo sujeito, mas não têm nele sua origem. Isto se deve ao descentramento da noção no âmbito discursivo, o que a faz distanciar-se do sujeito consciente, senhor de seus atos e com controle sobre a língua. O sujeito do discurso, em sua relação com a língua, estabelece um processo de constituição mútua, constituindo-se e constituindo-a no seio de acontecimentos histórico-sociais. Assim, ele não é totalmente livre, dado o modo de sua constituição, nem totalmente determinado por mecanismos externos.

Precisamente no espaço de tensão entre essas duas forças é que a $A D$ vai trabalhar, enfrentando a contradição entre a vontade de hipertrofia do sujeito e a submissão ao assujeitamento. Essa tendência oscilante tão própria do discurso faz com que o sujeito mantenha uma relação ativa no interior de uma dada formação discursiva: assim como é determinado, também a determina, por força de sua prática discursiva.

Além disso, a interpelação do indivíduo em sujeito pela ideologia traz necessariamente alguns apagamentos, produzindo as já mencionadas evidências, que, no fundo, vão trazer à tona a ilusão da transparência da linguagem.

\section{d) sentido:}

A noção de sentido, tão freqüentemente referida no âmbito da teoria discursiva, apresenta-se na relação determinada do sujeito com a 
história, imprimindo a marca da subjetivação nos contatos da língua com a exterioridade. Cabe ao gesto de interpretação, realizar essa relação do sujeito com a língua na produção dos sentidos.

O sentido tem seu processo de constituição como algo fundamentalmente histórico, vinculado a um trabalho da rede de memória; assim, como ocorre com o sujeito, o sentido nunca é individual, nem tampouco apresenta-se como já produzido. A Análise do Discurso vai deter-se precisamente no processo de produção dos sentidos, através de procedimentos que desvendem a historicidade contida na linguagem em seus mecanismos imaginários. Esta determinação histórica tanto do sentido, quanto do sujeito faz com que eles não sejam entendidos como naturais, transparentes, mas sejam pensados em sua contradição e espessura.

A teoria do discurso é também uma teoria da materialidade do sentido, que procura dar conta da ilusão necessária do sujeito - senhor da língua e fonte de seu dizer.

\section{e) o discurso:}

Resta agora uma breve apreciação sobre o discurso, afinal, o conceito mais importante e decisivo, em se tratando de uma teoria que o elege como objeto preferencial. Apoiada no discurso, a Análise do Discurso entra em ação, tentando pôr à luz o confronto do simbólico com o político. Os deslocamentos teóricos propostos pela Análise do Discurso, tendo em conta as outras disciplinas e seu conjunto estabelecido de princípios, valores e conceitos, passam necessariamente pela noção de discurso, entendido como processo social, cuja materialidade é lingüística. Aqui surge um traço distintivo essencial da relação da Análise do Discurso com a Lingüística: seu objeto não é a língua, mas o discurso, um objeto histórico-social, onde os elementos lingüísticos intervêm como pressupostos. Como costuma dizer Orlandi (1986), a AD os considera, mas vai além.

O discurso é o objeto que nos permite observar as relações entre ideologia e língua, bem como os efeitos do jogo da língua na história e os efeitos desta na língua. É através do discurso que se vai compreender como um material simbólico produz sentidos e como o sujeito se constitui. Ao situar-se como lugar privilegiado de observação entre a língua, a ideologia e o sujeito, o discurso propicia, como bom observatório, a visualização das propriedades do complexo dispositivo teórico-analítico.

Interessante observar certas particularidades dessa noção, cuja definição nunca está acabada, sendo re-significada a cada análise. Denise Maldidier (1990) referiu-se a isso, ao revelar, com sensibilidade e argúcia, que o discurso era o objeto da busca incessante de Pêcheux, que sem ces- 
sar lhe escapava. Tal obstinação devia-se à consideração do discurso, justamente, como verdadeiro nó onde as questões fundamentais sobre as relações entre língua, história e sujeito se intrincavam.

O discurso apresenta-se como objeto teórico; portanto, longe do compromisso com a evidência empírica. Com ele há sempre indício de uma ruptura que será desvendada pelo trabalho do analista, buscando compreender como o gesto de interpretação funciona em sua materialidade, no exato momento em que o sentido faz sentido em um determinado discurso.

Vimos, assim, em rápidas passadas, por que o discurso tem essa carga de significância que o torna tão denso e o faz devolver à linguagem sua espessura material e ao sujeito sua contradição. Ele é lugar de encontro, de imbricação, de mediação e observação. E é também de certa forma uma metáfora que requer a cada construção um transporte de um campo para outro.

\section{A VEZ DA LÍNGUA}

Se o discurso representa a grande aventura teórica, a língua certamente é a grande parceira, aquela capaz de tornar singular todo o percurso. Língua e discurso nem sempre andaram em sintonia na escola francesa da Análise do Discurso. Parafraseando Pêcheux, diria que os analistas de discurso, nos primeiros tempos, mostravam-se surdos em relação à língua. $\mathrm{O}$ embate político, a demarcação de território, a luta pelos espaços institucionais fizeram com que as questões da língua ficassem diluídas, perdendo nitidamente espaço para a ideologia e para as questões de política. A análise dos discursos políticos, como mostram os primeiros trabalhos, ocupava o centro da atenção dos analistas.

Aqui mesmo na América Latina, e mais especialmente no Brasil, até bem pouco tempo, falar-se em Análise do Discurso era traduzido por falar em discurso político, ideologia, formações sociais e condições de produção. Claro que isso representava um momento histórico determinado e tinha toda a razão de assim ser. A Análise do Discurso, lá na França, por força de questões muito próprias, teve um papel declaradamente de militância, de erguer bandeiras e marcar posição político-ideológica. O projeto fundador da teoria tinha esse viés assumido de modo bastante explícito.

É claro também que essa tendência se alterou, por força até da conjuntura, e, mesmo assim, há aqueles que insistem em continuar rotulando essa análise do discurso francesa, como radical, ortodoxa, ou então, tardiamente marxista. Isso também não deixa de sinalizar, nos tempos atuais, um embate político e institucional. O certo é que a Análise do Discurso, ainda 
que tenha se expandido e ganho muitos adeptos (com todos os riscos de descaracterização e banalização que isso acarreta), ainda causa um certo desconforto e um incômodo indisfarçável, sobretudo na área da lingüística.

Penso que, no quadro atual, a grande virada para a língua foi dada pelo próprio Pêcheux com as questões envolvendo o equívoco, como fato lingüístico estrutural, o que abriu, por consequiência, lugar para tratar da noção de real da língua, derivada da psicanálise. Esta foi, sem dúvida, uma virada decisiva e incontornável.

Com o desaparecimento de Pêcheux, a Análise do Discurso se desestruturou na França de modo, aparentemente, irremediável. O grupo multidisciplinar que se reunia em torno dele se dispersou, buscou novos rumos. Perdeu-se o rótulo, a etiqueta de designação; o que não se perdeu, contudo, foi o modo característico de refletir sobre a linguagem que determina o tratamento a ser dado às questões que importam ao discurso e asseguram sua identidade e especificidade no campo das ciências humanas.

Courtine (1991), em artigo sugestivamente intitulado Le discours introuvable: marxisme et linguistique, destila todo seu pessimismo e ressentimento com os rumos tomados pela disciplina, na perspectiva pós-estruturalista, pós-marxista e, sobretudo, pós-Pêcheux. Segundo ele, houve um processo de desmarxização nas pesquisas da lingüística e das ciências humanas em geral e um esvaziamento da proposta fundadora da Análise do Discurso, com as sucessivas análises de discurso que apareceram.

Existia uma análise do discurso que queria articular história e lingüística. Existem agora as análises de discurso que abandonaram, na sua maior parte, um tal projeto. (Ibidem, p. 161)

Em decorrência da primazia da linha empírico-formalista sobre a dimensão histórico-crítica, houve ainda, seguindo o balanço do "espólio" decretado por Courtine, um recobrimento das questões históricas pelo aspecto lingüístico da análise.

No conjunto, as lamentações e queixas apresentadas procedem em parte; mas não podem ganhar uma dimensão de veredicto absoluto. É bem verdade que a "utopia política" de aliar uma teoria marxista do discurso a um "sonho positivista" de uma "análise automática do discurso" desmoronou com a mudança de rumo na área política. Mas é preciso não perder de vista que a Análise do Discurso, pelo menos a corrente francesa à qual me filio, continua se pautando por uma teoria materialista dos sentidos, que considera a língua na sociedade e na história, fazendo intervir a ideologia. Por essa perspectiva, existe sim, um novo empenho em examinar as questões lingüísticas, mas sem perda das considerações históricas e ideológicas.

Precisamente da língua e de seu encontro com a história surge a possibilidade de trabalhar o equívoco, que irrompe como lugar de resistên- 
cia inerente à língua e à sua constituição. Isto evidentemente só se viabiliza se levarmos em conta uma noção de língua dotada de natureza instável, heterogênea por formação e contraditória. ${ }^{3}$

Pêcheux (1988, p.53), naquele que é considerado seu último livro Discurso: estrutura ou acontecimento?, dá o tom de como operar com um conceito de língua que reconheça nos fatos do equívoco o real que lhe é próprio. Ao admitir que a língua é voltada ao equívoco, delimita o espaço em que a Análise do Discurso pretende trabalhar, a partir dali, isto é, o espaço do deslocamento discursivo de sentido próprio a qualquer enunciado. Isto porque, como diz ele: “...todo enunciado é suscetível de tornar-se outro...".

\section{De que língua trata o analista de discurso}

A questão da língua aguça sempre o universo de investigação dos estudiosos da linguagem. As inúmeras tentativas de delimitá-la, descrevêla e analisá-la esbarram muitas vezes na opacidade própria de sua constituição, acentuada pela diversidade dos múltiplos olhares teóricos que a perscrutam. Resultado dessa trajetória ímpar são as várias noções que se costumam associar ao conceito de língua, como código, sistema, atividade, interação e equívoco.

$\mathrm{Na}$ Análise do Discurso, a língua vista em sua condição de materialidade é um dos elos essenciais a compor o tecido discursivo. $\mathrm{O}$ aspecto de singularidade da língua que queremos ressaltar no presente texto tem a ver, entre outras circunstâncias, com a noção de estrutura e seu alcance e especificidade na ótica discursiva. Sob esse enfoque, a língua do analista de discurso vai distinguir-se da língua do lingüista, entre outras razões, por comportar em si (enquanto totalidade) o não-todo, consubstanciado na noção de real da língua, o que faz dela um modo singular de produzir equívoco.

A língua na Análise do Discurso é tomada em sua forma material enquanto ordem significante capaz de equívoco, de deslize, de falha, ou seja, enquanto sistema sintático intrinsecamente passível de jogo que comporta a inscrição dos efeitos lingüísticos materiais na história para produzir sentidos. A passagem de uma forma lingüística, tradicionalmente considerada nos estudos da linguagem, para uma forma material, onde não há mais a consideração da dicotomia forma/conteúdo traz algumas conseqüências de peso. Enumeremos algumas:

${ }^{3}$ Em dois outros artigos discuto mais detidamente o que entendo sobre a noção de língua que interessa ao discurso: FERREIRA(1996) (1999). 
a) a língua deixa de ser considerada um sistema integralmente autônomo para ser aceita como relativamente autônoma;

b) o sistema lingüístico não é algo abstrato e fechado, mas sim um sistema passível de perturbações, rupturas e mal-entendidos;

c) os fatos lingüísticos considerados com problemas não ficam de foram do sistema, à margem da língua, e passam a ser considerados como nucleares, em vez de periféricos;

d) abandonam-se as concepções muito difundidas de língua enquanto código, ou então, instrumento de comunicação ideologicamente neutro;

e) a língua é lugar material de realização dos processos discursivos, onde se manifestam os sentidos.

Vê-se, portanto, por essa série de traços definidores, que na Análise do Discurso a língua não é a mesma língua lá da lingüística, pelo menos, friso sempre bem isto, na Análise do Discurso de Pêcheux e seus seguidores. A língua do analista de discurso tem um funcionamento ideológico e suas formas materiais estão investidas desse funcionamento.

Talvez seja por isto que Courtine chegou a afirmar, numa formulação muito original, que para ser analista de discurso é preciso ser lingüista e esquecer que se é...

A singularidade da língua na Análise do Discurso vai além das mudanças na sua formulação e do alcance de seus novos limites. Por ser um dos elos essenciais a compor a cadeia discursiva, a concepção de língua no discurso vai afetar igualmente a atividade do analista e seu trabalho de interpretação. Para o analista de discurso a língua não será objeto de investigação primordial, mas um pressuposto fundamental para analisar a materialidade do discurso.

Vale lembrar que a Análise do Discurso, como ponto de vista diferenciado sobre a linguagem, vai recortar seu objeto teórico distinguindo-se da lingüística imanente. Isto implica uma negação da tendência sistêmica da língua, fundada por Saussure, que só admite o estudo da língua de modo interno, sem considerar critérios de explicação exteriores a ela. Conseqüentemente, os fatos de língua que ficam à deriva do sentido, por força de mal-entendidos, deslizamentos ou lapsos, saem da zona nobre (nuclear) do círculo concêntrico que representa a língua para a lingüística e são jogados para fora. A tarefa do analista de discurso será buscar tais fatos com agudo interesse e incorporá-los ao seu material central de investigação e tratá-los como fatos que integram a estrutura, ou seja, que são próprios da língua.

A noção de estrutura ganha um relevo especial nessa tendência mais recente da Análise do Discurso que aqui identificamos com a marca 
da língua . Ela comporta em si a necessária ancoragem de que um dispositivo de interpretação precisa para ter acesso à materialidade simbólica do discurso. Tanto quanto da materialidade lingüística, o discurso e o analista vão precisar também da materialidade histórica (e da análise dos enunciados que constituam acontecimentos). Juntas e de modo simultâneo, materialidade lingüística e histórica vão compor a materialidade discursiva.

O discurso (ou a materialidade discursiva) fica exposto, como anuncia Pêcheux (1988), à tensão entre a estrutura e o acontecimento, entre a análise como descrição e como interpretação, entre o estatuto das discursividades que oscila entre proposições de aparência logicamente estável, suscetíveis de resposta unívoca e formulações irremediavelmente equívocas". (p.28)

O aparato operacional do dispositivo teórico e analítico vai favorecer que através da língua e de seu sistema instável e heterogêneo as relações entre os enunciados sejam melhor percebidas, pois uma propriedade do dispositivo, citada por Marandin (1994, p.124), é justamente fazer ver o processo de produção do sentido.

Eu acrescentaria: o dispositivo como prática analítica funciona na captação do real da língua, o que significa, em outras palavras, que ele nos aproxima daquilo que está mais perto do que é próprio da língua, isto é, de seu estatuto de equivocidade.

\section{COMO TRATA A LÍNGUA O ANALISTA DE DISCURSO}

O exemplo clássico de como lidar com um enunciado como um acontecimento lingüístico e ideológico é a análise que Pêcheux (1988) faz da expressão "on a gagné", em Discurso: estrutura ou acontecimento", tal como ela atravessou a França no dia 10 de abril de 1981, às 20 horas e alguns minutos ( o acontecimento no ponto de encontro de uma atualidade e uma memória. (p.17)

Pêcheux demonstra como o conteúdo sócio-político desse acontecimento jornalístico (televisivo) revela-se ao mesmo tempo perfeitamente transparente (gráficos, números, tabelas) e profundamente opaco (o imenso confronto discursivo que antecedeu esse acontecimento improvável presente em enunciados que remetem ao mesmo fato, mas não constroem as mesmas significações).

De outra parte, a materialidade discursiva do enunciado coletivo em análise não é própria do campo semântico da política, fazendo parte de um grito de guerra comum aos torcedores de uma partida esportiva, após uma vitória. Em princípio, tal enunciado traz desdobramentos que podem ser descritos através de respostas unívocas a questões pontuais, sendo a 
principal: quem ganhou? $X$ ои $Y$ ? "Tal equipe ganhou o jogo em questão contra tal outra. Ponto. Acabou." Ou então: considerando os números, as percentagens, as regras das eleições, F.Miterrand foi eleito presidente da República. Eis uma proposição verdadeira; ponto final. (Ibidem, p.23)

Ocorre que, simultaneamente, a materialidade lingüística do enunciado, ou a materialidade léxico-sintática, como diz Pêcheux, é profundamente opaca (o pronome indefinido na posição-sujeito, a escolha do lexema verbal [ganhar], a ausência de complementos), o que inscreve o enunciado numa série heterogênea e com uma estabilidade lógica variável. Confirma-se, assim, a questão teórica por ele colocada do caráter oscilante e paradoxal da fronteira entre o espaço dos universos logicamente estabilizados e o universo das transformações de sentido, com o entrecruzamento constante de proposições de aparência logicamente estável, suscetíveis de resposta unívoca (sim ou não, é x ou y) e formulações irremediavelmente equívocas. (p.28)

Aí se coloca para Pêcheux o problema principal nas práticas de análise de discurso: determinar o lugar e o momento da interpretação, em relação aos da descrição: não como duas fases sucessivas, mas como uma alternância ou batimento... (p.54).

\section{CONSIDERAÇÕES FINAIS}

A singularidade da língua que procuramos ressaltar nesta comunicação mede-se, como se viu, por sintomas que extrapolam os limites de sua conceituação. Entram em jogo as distinções com as disciplinas afins à Análise do Discurso, sobretudo a Lingüística, além das inter-relações com os outros conceitos que compõem a teoria do discurso, como sujeito, história, ideologia, sentido e o próprio discurso. Como numa reação em cadeia, os traços definidores da língua, como o fato de ser apenas relativamente autônoma, afetam, por exemplo, a condição do sujeito, que não é mais a origem de si; o sentido, que não é conteúdo; a história, que não é contexto, e a ideologia, que não é defeito.

Do modo como o analista de discurso entende a língua vão decorrer efeitos de sentido que afetarão os procedimentos de análise, como Pêcheux bem demonstrou, assim como a interpretação a ser atribuída a seus resultados. O real alcance do que isso tudo significa será percebido em cada etapa de análise: do recorte do material discursivo à inserção dos enunciados em determinada série de filiações sócio-históricas, sem que isso implique um apagamento do acontecimento pela estrutura, "através de sua absorção em uma sobredeterminação antecipadora". (Ibidem, p.56)

Reiteramos, pois, a posição que defendemos do analista de discurso em relação a seu ofício, que não é exatamente a de interpretar o 
discurso ou os textos, em que pese a Análise do Discurso ser uma disciplina de interpretação; mas sim, flagrar o gesto de interpretação na sua materialidade, no exato momento em que a interpretação se dá, em que o sentido se faz sentido.

\section{BIBLIOGRAFIA}

COURTINE,J.J. Le discours introuvable: marxisme et linguistique. Histoire, Épistémologie, Langage, 13/II, 1991.p.153-71. Trad. por Heloisa Monteiro Rosário. Cadernos de Tradução,6. Instituto de Letras da UFRGS, 1999. p.5-18.

ESCOBAR,C.H. (org.). Psicanálise e ciência da história. Rio de Janeiro, Eldorado, 1974. p. 139-48.

HENRY,P. A história não existe? Trad. por José Horta Nunes. In: ORLANDI,E. (org.) Gestos de Leitura. Campinas, Ed. da Unicamp, 1994. p.29-54.

MALDIDIER,D. L'Inquiétude du discours. Paris, Ed. des Cendres, 1990.

MARANDIN,J.M. Sintaxe, discurso do ponto de vista da análise do discurso. Trad. por Maria Cristina Leandro Ferreira. In: ORLANDI, E. (org.) Gestos de Leitura. Campinas, Ed. da Unicamp, 1994. p. 43-119.

ORLANDI,E. A análise do discurso: algumas observações. Delta, v. 2, n. 1, p.105-26, 1986.

PÊCHEUX,M. L' étrange miroir de l'analyse de discours. Langages, $\mathrm{n}$. 62 , p. 5-8, 1981.

PÊCHEUX,M. (1988) Discurso: estrutura ou acontecimento. Trad. por Eni Orlandi. Campinas, Ed.da Unicamp, 1990.

PÊCHEUX,M \& FUCHS,C.. Mises au point et perspectives à propos de l'analyse automatique du discours. Langages, n. 37, 1975. Trad. por Péricles Cunha. Por uma análise automática do discurso: uma introdução à obra de Michel Pêcheux. Campinas, Ed. da Unicamp, 1990. 